University of New Hampshire

University of New Hampshire Scholars' Repository

Spring 2018

\title{
The Impact of Academic Self-Efficacy on the Occupation of Education in College Athletes Who Experience Concussion
}

Samantha Colaw

University of New Hampshire, Durham

Follow this and additional works at: https://scholars.unh.edu/honors

Part of the Occupational Therapy Commons

\section{Recommended Citation}

Colaw, Samantha, "The Impact of Academic Self-Efficacy on the Occupation of Education in College Athletes Who Experience Concussion" (2018). Honors Theses and Capstones. 421.

https://scholars.unh.edu/honors/421

This Senior Honors Thesis is brought to you for free and open access by the Student Scholarship at University of New Hampshire Scholars' Repository. It has been accepted for inclusion in Honors Theses and Capstones by an authorized administrator of University of New Hampshire Scholars' Repository. For more information, please contact Scholarly.Communication@unh.edu. 


\section{The Impact of Academic Self-Efficacy on the Occupation of Education in College Athletes Who Experience Concussion \\ Samantha Colaw OTS \& Gabrielle Petruccelli MS OTR/L}

\section{PURPOSE}

An emerging area of inquiry for occupational therapists (OT) is consideration of the impact of concussion on a person's ability to engage in and perform meaningful everyday activity. The perspective of student-athletes (SA) living with post-concussion symptoms has received limited attention in research and there is a lack of focused attention regarding the role of being a student. This research adds to the growing body of literature regarding the implications of concussion on academics, specifically academic self-efficacy (ASE) and their self-perceived roles. The purpose of this study is to investigate the differences in ASE between college athletes with and without concussion.

\section{DESIGN}

A mixed methods concurrent (QUAN + QUAL) design was administered in 2 phases. Initial recruitment was conducted through the Director of a University’s Athletic Training Department. Subsequent strategies included outreach to varsity coaches and SA directly. Phase 1 included a 20-minute online survey, and Phase 2 included 10 in-depth interviews of student athletes with and without concussions. SA were included in both Phase 1 and Phase 2 if they were $18+$ years of age and a varsity SA at the University of New Hampshire. The concussion group had experienced a concussion within 12 months of data collection.

\section{METHODS}

In Phase 1, the SA completed demographic questions, identified if they experienced a concussion, and completed the Self-Efficacy for Learning Form (SELF) assessment tool (Zimmerman \& Kitsantas, 2007). The SELF included 57 short scenarios focusing on 5 major 
subsets of skills: reading, writing, studying, test-taking, and note-taking. SA ranked their confidence in being able to complete the task on a scale from $1-100 \%$. In phase 2 , SA participated in in-depth interviews at the campus library, and provided insight to the subjective experience of concussion. In Phase 2, we used open-ended questions regarding the role of being a SA and its potential impact on academics. In the concussion group we specifically explored how the experience of concussion related to academic engagement. Survey data from Phase 1 was analyzed using independent samples t-tests and Phase II interviews were transcribed, coded and analyzed for themes.

\section{RESULTS}

50 participants completed the study, of which 18 experienced a concussion. The average SELF scores for SA with concussion was 63.85 compared to SA without concussion (70.1). When comparing the various sub-scales of the SELF, we observed that SA with concussion reported lowest confidence in note-taking and highest confidence in studying. On the other hand, SA without concussion reported lowest confidence in note-taking and highest confidence in writing. We found a significant difference in note-taking. Findings from the t-test indicate that there is a significant difference $(\mathrm{t}=-2.15 ; \mathrm{p}=.037)$ in the note-taking skills among SA with and without concussion. Preliminary themes from the in-depth interviews indicate that SA in the concussion group experienced challenges in sustained and selective attention, energy conservation, time management, and increased stress. On the contrary, SA without concussion reported challenges in achieving occupational balance with daily structure, time commitment, support systems, and playing through injury. Overall, qualitative data addressed the differences in perceived role competency between concussion and non-concussion groups. 


\section{CONCLUSION}

Student athletes with concussion experience lower academic-self efficacy, especially while performing complex tasks like note-taking. A significant difference in note-taking aligns with previous literature regarding the relationship between concussions and executive function (specifically higher order thinking, multi-step actions, and problem solving). Student athletes without concussion reported challenges in non-academic areas. OTs working with student athletes with concussion should help implement a return to learning plan that includes strategies for note taking and addresses academic self-efficacy in the role of being a student. 